\title{
Relação entre os níveis de escrita, consciência fonológica e conhecimento de letras
}

\author{
Relationship between spelling levels, phonological \\ awareness, and letter knowledge
}

\author{
Mirna Rossi BARBOSA ${ }^{1}$ \\ Lidiane Batista de Oliveira MEDEIROS² \\ Ana Paula Simões do VALE ${ }^{3}$
}

\section{Resumo}

Este estudo teve como objetivo investigar a relação entre nível de escrita, consciência fonológica e conhecimento de letras. Participaram 60 crianças do $1^{\circ}$ ano do ensino fundamental com média de idade de 6,09 anos, as quais foram submetidas a testes de conhecimento de letras, consciência fonológica e escrita inventada no início e no final do ano escolar e ao Teste Matrizes Progressivas Coloridas de Raven, aplicado apenas no início do ano. Verificaram-se correlações significativas entre consciência fonológica, conhecimento de letras e nível de escrita. A maioria das crianças evoluiu ao longo do ano nos desempenhos observados. Significativamente, aquelas que apresentaram melhor domínio da consciência fonológica e conhecimento do nome das letras desde o início do ano, evoluíram mais na escrita ao final do ano. Nesse sentido, a instrução da consciência fonológica associada ao conhecimento de letras deve ser realizada ainda na pré-escola, a fim de garantir uma boa aprendizagem ulterior em escrita.

Palavras-chave: Alfabetização; Consciência fonológica; Habilidade para escrita; Linguagem escrita.

\begin{abstract}
This study aimed to investigate the relationship between spelling levels, phonological awareness, and letter knowledge. Sixty first grade children, mean age 6.09 years, participated in the study. They underwent letter-knowledge, phonological awareness, and spelling tests at the beginning and end of the school year. The Raven's Progressive Matrices test was applied only at the beginning of the school year. Results showed significant correlations between phonological awareness, letter knowledge, and spelling level. Most children progressed remarkably throughout the year. However, those who had better phonological awareness skills and letter-name knowledge at the beginning of the school year significantly improved their spelling skills at the end of the year. Therefore, phonological awareness instruction combined with letter-knowledge should be provided in pre-school to ensure the development of good spelling skills in the subsequent school years.
\end{abstract}

Keywords: Literacy; Phonological awareness; Writing skills; Written language.

\section{$\checkmark \nabla v$}

1 Universidade Estadual de Montes Claros, Centro de Ciências Biológicas e da Saúde, Programa de Pós-Graduação em Ciências da Saúde. Campus Universitário Professor Darcy Ribeiro, Av. Dr. Rui Braga, s/n., Vila Mauricéia, Caixa Postal 126, 39401-089, Montes Claros, MG, Brasil. Correspondência para/Correspondence to: M.R. BARBOSA. E-mail: <mirnarossi@hotmail.com>.

2 Universidade Estadual de Montes Claros, Centro de Ciências Humanas, Programa de Pós-Graduação em Didática e Metodologia do Ensino. Montes Claros, MG, Brasil.

${ }^{3}$ Universidade de Trás-os-Montes e Alto Douro, Departamento de Educação e Psicologia. Vila Real, Portugal. 
Aprender a escrever em um sistema de escrita alfabética é uma atividade muito complexa, pois requer, da parte do aprendiz, mecanismos perceptivos, cognitivos, linguísticos, motivacionais e até conhecimento do mundo. No entanto, o componente específico da aprendizagem da escrita é o processamento de palavras que, no início da aprendizagem, constitui o seu elemento crucial (Abbott, Berninger, \& Fayol, 2010; Juel, Griffith, \& Gough, 1986).

Pesquisadores de diferentes áreas, como Psicologia, Fonoaudiologia e Medicina, estudam a aquisição da leitura e escrita e as habilidades envolvidas nestes processos para tentar explicar as dificuldades que inúmeras crianças vêm apresentando no seu desenvolvimento. Entre as décadas de 1920 e 1970, acreditava-se que os distúrbios de leitura e escrita eram causados por falhas no processamento visual. A partir de 1970, essa hipótese foi rejeitada e as causas dos distúrbios passaram a ser atribuídas a deficit concernentes à informação fonológica (A.G.S. Capovilla, Capovilla, \& Suiter, 2004).

O processamento fonológico corresponde ao uso da informação baseada na estrutura dos sons de uma língua e é formado pela consciência fonológica, que é a capacidade de refletir sobre os sons os quais compõem a fala e sua organização na formação das palavras (Marchetti, Mezzomo, \& Cielo, 2010); pela memória de trabalho fonológica; e pela nomeação rápida (Tenório \& Ávila, 2012). Vários pesquisadores investigam as relações entre o processamento fonológico e os processos de leitura e escrita, devido à preocupação em detectar precocemente indivíduos propensos a desenvolver distúrbios de leitura e escrita em virtude de deficit nessas habilidades linguísticas (Vitor, 2006).

Dentre as habilidades do processamento fonológico, a consciência fonológica tem sido bastante pesquisada. Existem estudos que demonstram uma interdependência entre consciência fonológica e a aquisição da linguagem escrita (Nunes, Frota, \& Mousinho, 2009; Pestun, Omote, Barreto, \& Matsuo, 2010; Tenório \& Ávila, 2012; Verhagen, Aarnoutse, \& Van Leeuwe, 2010). À medida que a consciência fonológica vai se desenvolvendo, mais avançada é a fase de alfabetização
(Cardoso, Silva, \& Pereira, 2013). Por outro lado, escolares com dificuldades de aprendizagem apresentam desempenhos inferiores em consciência fonológica quando comparados aos escolares sem dificuldades de aprendizagem (Capellini \& Lanza, 2010). A alfabetização, por sua vez, influencia no desempenho em habilidades metalinguísticas. Em estudo realizado com adultos brasileiros, os sujeitos escolarizados apresentaram desempenho superior ao dos não alfabetizados em três tarefas de consciência fonológica (Mota \& Castro, 2007).

Crianças da pré-escola que foram submetidas a treino sistemático de consciência fonêmica dos sons iniciais da primeira sílaba de palavras (ataque) progrediram significativamente quanto à capacidade para detectar fonemas em várias posições na estrutura silábica, como também desenvolveram a capacidade para representar palavras pela escrita (Coutinho, Vale, \& Bertelli, 2003). Além da consciência fonológica, vários estudos confirmam que o conhecimento do nome das letras exerce um importante papel na aquisição da escrita (Cardoso-Martins \& Batista, 2005; Cardoso-Martins \& Corrêa, 2008; Georgiou, Torppa, Manolitsis, Lyvtinen, \& Parrila, 2012; Levin, Patel, Margalit, \& Barad, 2002; Pollo, Kessler, \& Treiman, 2005; Treiman, Kessler, \& Pollo, 2006).

Perceber os nomes das letras na estrutura sonora das palavras parece ser a primeira manifestação de fonetização na escrita. Crianças podem escrever a letra "T" para a palavra "telefone", mas não para a palavra "tartaruga", uma vez que o nome da letra é claramente audível na forma oral apenas da primeira palavra (Cardoso-Martins \& Batista, 2005).

Adultos iletrados também se beneficiam do conhecimento do nome das letras para conectar a escrita à fala. Em um estudo com essa população, foi observado um número relativamente pequeno de escritas silábicas, sendo que a maioria era composta por letras cujo nome podia ser claramente detectado na pronúncia da palavra (Corrêa, Cardoso-Martins, \& Rodrigues, 2010).

O objetivo deste trabalho foi comparar e correlacionar o desempenho de crianças do $1^{\circ}$ ano do ensino fundamental de escolas públicas em 
consciência fonológica, conhecimento de letras e nível de escrita em dois momentos do ano letivo. Também se propôs a investigar a contribuição da consciência fonológica e do conhecimento de letras para o nível de escrita e examinar se essa relação se mantém do início para o final do ano letivo.

\section{Método}

\section{Participantes}

Trata-se de estudo longitudinal, realizado em duas escolas públicas estaduais de um município do interior mineiro, sendo uma localizada no centro da cidade e outra na periferia. Foram selecionadas aleatoriamente crianças do $1^{\circ}$ ano do ensino fundamental que não apresentavam diagnóstico de deficiência (intelectual e/ou sensorial) ou de distúrbio de aprendizagem e/ou dislexia. As crianças as quais obtivessem um desempenho inferior ao percentil 50 no teste de inteligência não-verbal Matrizes Progressivas Coloridas de Raven, bem como aquelas cujos pais/responsáveis não autorizassem a sua participação, foram excluídas da pesquisa.

A amostra contou com 60 crianças (33 meninos e 27 meninas), sendo 30 de cada escola, com idades entre 5 anos e 7 meses e 6 anos e 7 meses (Média =6,09; Desvio-Padrão = 0,27), alfabetizadas pelo método silábico, segundo depoimento das professoras. Durante o ano letivo, todas as crianças frequentaram escola regular, sendo que ambas as escolas adotaram os mesmos materiais para alfabetização. Não houve intervenções diferenciadas para nenhuma criança ao longo do ano.

\section{Instrumentos}

\section{Teste Matrizes Progressivas Coloridas de Raven}

As Matrizes Progressivas Coloridas de Raven (MPC Raven) têm o objetivo de avaliar a inteligência não-verbal de crianças utilizando padrões geométricos. As crianças têm que escolher, dentre seis alternativas, o padrão que completa uma figura- -alvo inacabada (J.C. Raven, Raven, \& Court, 1988). O teste é constituído por três séries de 12 itens: $A$, Ab e B. Em cada uma delas os itens estão dispostos em ordem de dificuldade crescente, dessa forma a série seguinte é sempre mais difícil do que a anterior. No início de cada série são sempre colocados itens mais fáceis, com o objetivo de introduzir a criança a um novo tipo de raciocínio, exigido para os itens seguintes.

Os resultados foram cotados conforme o manual do teste. A cada resposta correta foi atribuído um ponto. As respostas erradas não receberam pontuação. Desta forma, a pontuação final poderia variar de 0 a 36 pontos, sendo depois transformada em percentis observando as tabelas de padronização. De acordo com a pontuação recebida, as crianças classificadas com percentil inferior a 50 foram excluídas da amostra. Na avaliação das propriedades psicométricas, o teste MPC de Raven apresentou estabilidade temporal teste-reteste aceitável $(r=0,75)$ e consistência interna satisfatória, com alfa de Cronbach de 0,73 (Brites, 2009).

\section{Conhecimento de Letras}

Para o teste de Conhecimento de Letras, foram registradas, em uma folha de papel A4, as 26 letras do alfabeto (incluindo K, W, Y) de forma aleatória e em tipo Calibri 48. As letras maiúsculas estavam dispostas nas quatro linhas superiores e as minúsculas nas quatro inferiores.

Cada letra era mostrada à criança a quem era feita a seguinte pergunta: "Que letra é essa?". As letras respondidas corretamente eram circuladas e o valor de um ponto era atribuído, sendo que a máxima pontuação possível era de 52 pontos. 0 total de pontos obtidos era então dividido por dois; dessa forma, o resultado final que cada criança poderia obter era de, no máximo, 26 pontos.

\section{Perfil de Habilidades Fonológicas}

O Perfil de Habilidades Fonológicas (Alvarez, Carvalho, \& Caetano, 1998) é composto por 14 subtestes que visam avaliar a consciência fonoló- 
gica, sendo eles: análise inicial, final, medial, adição de sílabas e de fonemas, segmentação de frases, segmentação de vocábulos, subtração de sílabas e de fonemas, substituição, recepção de rimas, rima sequencial, reversão silábica e imagem articulatória. Os subtestes de análise medial, adição de fonemas, subtração de fonemas e substituição foram excluídos da coleta por serem aplicáveis somente a crianças a partir de sete anos de idade.

O instrumento é composto por um caderno de aplicação com os subtestes, quatro fichas ilustrativas, as quais representam as alternativas para resposta do subteste de imagem articulatória, e nove peças coloridas para serem usadas como pistas concretas. Cada subteste é composto por quatro itens. A cada acerto era atribuído um ou dois pontos, de acordo com o subteste avaliado; dessa forma, cada criança poderia obter um total de até 60 pontos.

\section{Escrita Inventada}

O nível de escrita foi avaliado por um teste experimental designado Escrita Inventada. Este consiste em pedir à criança que não possui ainda um conhecimento assinalável das representações ortográficas e fonológicas das palavras para escrever uma série de palavras ditadas.

O teste consistiu em 20 palavras que variavam em número de nomes de letras que podiam ser detectados em sua pronúncia. Das palavras ditadas, seis continham um nome de letra (ex: "mesa", onde se pode ouvir o nome da letra A), oito continham dois nomes de letras (ex: "sebo", onde se pode ouvir o nome das letras $($ e $U$ ) e seis continham três nomes de letras (ex: "cabeça", onde se pode ouvir o nome das letras K, B e A). Quatorze palavras eram dissílabas e seis trissílabas e a estrutura silábica era formada por consoante-vogal e vogal. As crianças foram solicitadas a escrever as palavras da melhor forma que pudessem. Caso necessitassem, o examinador poderia repetir cada palavra mais uma vez. As respostas foram registradas pelas crianças em uma folha de papel pautada.

As cotações feitas no teste de Escrita Inven670 tada foram adaptadas do Sistema de Classificação
Fonológica (Mann, 1993) para este estudo. Cada palavra escrita pela criança poderia valer entre $0 \mathrm{e}$ 4 pontos. Assim, foram atribuídos 0 pontos quando a criança não fazia nenhuma relação entre as letras que escrevia e a estrutura fonológica da palavra (exemplo: a resposta "d" para a palavra cabeça); $1 / 2$ ponto, quando a criança escrevia uma letra a qual representava algum fonema na palavra que não fosse o fonema inicial (exemplo: a resposta "a" para a palavra cabeça); 1 ponto, quando a letra correspondia ao fonema inicial da palavra (exemplo: a resposta "b" para a palavra bolo); 2 pontos, quando a resposta representava parte da estrutura fonológica da palavra (exemplo: "kb" para a palavra cabeça); 3 pontos, quando a resposta correspondia a toda a estrutura fonológica da palavra, mas de forma pré-convencional (exemplo: "kbsa" para a palavra cabeça); 3,5 pontos a escritas em que cada fonema da palavra era representado por uma letra foneticamente apropriada, mesmo que ortograficamente incorreta (exemplo: "cabesa" para a palavra cabeça); e 4 pontos a escritas ortograficamente corretas. Desta forma, somando-se as pontuações das 20 palavras ditadas, o nível de escrita de cada criança poderia ser pontuado em, no máximo, 80 pontos.

\section{Procedimentos}

Os testes foram aplicados em salas silenciosas designadas pela diretoria das escolas em dois momentos do ano letivo de 2008: durante os meses de março e abril e durante o mês de dezembro. No primeiro momento, as crianças foram submetidas ao Teste MCP de Raven, a um Teste de Perfil de Habilidades Fonológicas, à avaliação do Conhecimento de Letras e à Escrita Inventada, aplicados nesta ordem. No segundo momento, os alunos foram submetidos aos testes de Perfil de Habilidades Fonológicas e Conhecimento de Letras e, em seguida, ao Teste de Escrita Inventada.

O Teste MPC de Raven foi aplicado por um estagiário do curso de Psicologia, tendo duração aproximada de 30 minutos. Já o teste de Conhecimento de Letras durava, aproximadamente, 5 minutos e o teste Perfil de Habilidades Fonológicas 
entre 15 e 25 minutos, de acordo com a compreensão e desenvoltura de cada criança. Todo o teste foi aplicado no mesmo dia e na mesma sequência para todas as crianças. A duração do teste de Escrita Inventada foi de aproximadamente 15 minutos.

Este estudo foi aprovado pelo Comitê de Ética em Pesquisa da Universidade Estadual de Montes Claros através do Parecer $n^{\circ}$ 556/07. A realização da pesquisa contou com o Termo de Consentimento Livre e Esclarecido para pais/responsáveis dos sujeitos em estudo, bem como termo de autorização das escolas participantes.

Os dados foram analisados por meio do programa Statistical Package for the Social Sciences, versão 15.0. Foi realizado o teste $t$ pareado para a comparação entre os testes aplicados no início e no final do ano, considerando um nível de significância de $5 \%(p<0,05)$. Para avaliar as correlações entre as variáveis estudadas, foi realizado o teste de correlação de Pearson.

Em seguida, foram ajustados três modelos de regressão linear cujos desfechos foram: nível de escrita no início e nível de escrita no final do ano. As variáveis independentes foram consciência fonológica (início e final do ano) e conhecimento de letras (início e final do ano). Foi adotado o coeficiente de correlação para verificar o pressuposto de relação linear entre os desfechos e as variáveis independentes. Para avaliar a independência dos resíduos foi adotado o teste de Durbin-Watson (D.W.), considerando-se que valores próximos de 2 indicam independência dos resíduos. Para avaliar a normalidade dos resíduos, foi realizado o teste Kolmogorov-Smirnov (K.S.), ao nível de 0,05. Para avaliar a homocedasticidade, procedeu-se a análise gráfica dos resíduos. Calculou-se o coeficiente de determinação $\left(R^{2}\right)$ para avaliar o percentual da variabilidade do desfecho explicado pelo modelo.

\section{Resultados}

A Tabela 1 apresenta a comparação dos testes de consciência fonológica, conhecimento de letras e nível de escrita entre o primeiro e o segundo momento do ano letivo. É possível observar, por meio do $t$ de Student pareado, que houve evolução significativa em todos os testes aplicados.

Os resultados dos coeficientes das correlações de Pearson entre consciência fonológica, conhecimento de letras e nível de escrita, aplicados no primeiro momento do ano letivo, estão apresentados na Tabela 2. Todas as correlações foram significativas. As correlações entre consciência fonológica e conhecimento de letras e entre conhecimento de letras e nível de escrita revelaram moderada magnitude e a correlação entre consciência fonológica e nível de escrita, alta.

A Tabela 3 apresenta os resultados dos coeficientes das correlações de Pearson entre consciência fonológica, conhecimento de letras e nível de escrita aplicados no segundo momento do ano letivo. Todas as correlações se mostraram significativas e de alta magnitude.

Finalmente, foram ajustados três modelos de análise de regressão linear para avaliar a relação da consciência fonológica e do conhecimento de letras com o nível de escrita (Tabela 4). No modelo 1 , referente aos testes aplicados no primeiro momento, observa-se que a cada aumento de uma

Tabela 1

Comparação entre os testes realizados no primeiro e no segundo momento do ano letivo. Minas Gerais (MG), 2008

\begin{tabular}{|c|c|c|c|c|c|c|}
\hline \multirow{2}{*}{ Testes } & \multicolumn{2}{|c|}{$1^{\circ}$ Momento } & \multicolumn{2}{|c|}{$2^{\circ}$ Momento } & \multirow{2}{*}{$t$} & \multirow{2}{*}{$p$-valor } \\
\hline & M & $D P$ & M & $D P$ & & \\
\hline Consciência Fonológica* & 42,1 & 10,4 & 49,1 & 7,0 & $-8,784$ & $<0,001$ \\
\hline Conhecimento de Letras ${ }^{* *}$ & 19,6 & 5,1 & 23,8 & 2,9 & $-8,400$ & $<0,001$ \\
\hline Nível de escrita*** & 46,3 & 25,7 & 65,4 & 20,7 & $-9,094$ & $<0,001$ \\
\hline
\end{tabular}

Notas: "Máximo: 60 pontos; ${ }^{* *}$ Máximo: 26 pontos; ${ }^{* * * *}$ Máximo: 80 pontos.

M: Média; DP: Desvio-Padrão. 
Tabela 2

Coeficientes de correlação de Pearson entre os testes aplicados no primeiro momento do ano letivo. Minas Gerais (MG), 2008

\begin{tabular}{lccc}
\hline Testes & 1 & 2 & 3 \\
\hline 1. Consciência Fonológica & 1 & & \\
2. Conhecimento de Letras & $0,43^{*}$ & 1 & \\
3. Nível de escrita & $0,82^{*}$ & $0,56^{*}$ & 1 \\
\hline
\end{tabular}

Nota: *Nível de significância: $p<0,01$
Tabela 3

Coeficientes de correlação de Pearson entre os testes aplicados no segundo momento do ano letivo. Minas Gerais (MG), 2008

\begin{tabular}{lccc}
\hline Testes & 1 & 2 & 3 \\
\hline 1. Consciência Fonológica & 1 & & \\
2. Conhecimento de Letras & $0,72^{*}$ & 1 & \\
3. Nível de escrita & $0,80^{*}$ & $0,81^{*}$ & 1 \\
\hline
\end{tabular}

Nota: *Nível de significância: $p<0,01$.

Tabela 4

Contribuição da Consciência Fonológica e do Conhecimento de Letras para o nível de escrita. Minas Gerais (MG), 2008

\begin{tabular}{|c|c|c|c|c|c|c|c|}
\hline Modelo & Variáveis & $\beta$ (E.P.) & $t$ & Valor de $p$ & $R^{2}$ & D.W. & K.S. (valor de $p$ ) \\
\hline \multirow{3}{*}{$1^{*}$} & Constante & $-52,66(8,68)$ & $-6,06$ & 0,000 & \multirow{3}{*}{0,706} & \multirow{3}{*}{2,07} & \multirow{3}{*}{0,437} \\
\hline & Consciência Fonológica $1^{\circ}$ momento & $1,75(0,19)$ & 9,05 & 0,000 & & & \\
\hline & Conhecimento de Letras $1^{\circ}$ momento & $1,28(0,39)$ & 3,25 & 0,002 & & & \\
\hline \multirow{3}{*}{$2^{\star *}$} & Constante & $-7,14(8,62)$ & $-0,83$ & 0,411 & \multirow{3}{*}{0,554} & \multirow{3}{*}{2,15} & \multirow{3}{*}{0,779} \\
\hline & Consciência Fonológica $1^{\circ}$ momento & $1,14(0,19)$ & 5,90 & 0,000 & & & \\
\hline & Conhecimento de Letras $1^{\circ}$ momento & $1,26(0,39)$ & 3,22 & 0,002 & & & \\
\hline \multirow{3}{*}{$3^{* *}$} & Constante & $-82,95(11,24)$ & $-7,38$ & 0,000 & \multirow{3}{*}{0,753} & \multirow{3}{*}{1,72} & \multirow{3}{*}{0,530} \\
\hline & Consciência Fonológica $2^{\circ}$ momento & $1,36(0,27)$ & 4,94 & 0,000 & & & \\
\hline & Conhecimento de Letras $2^{\circ}$ momento & $3,43(0,66)$ & 5,23 & 0,000 & & & \\
\hline
\end{tabular}

Notas: *Variável desfecho: nível de escrita $1^{\circ}$ momento; ** Variável desfecho: nível de escrita $2^{\circ}$ momento.

$\beta$ : Coeficiente de regressão; E.P.: Erro-Padrão; $R^{2}$ : Coeficiente de determinação; D.W.: Durbin-Watson; K.S.: Kolmogorov-Smirnov.

unidade no escore da consciência fonológica ocorre um aumento de 1,75 pontos no nível de escrita, e a cada aumento de uma unidade no escore do conhecimento de letras observa-se aumento de 1,28 pontos no escore do nível de escrita. Esse modelo explica 70,6\% da variabilidade do nível de escrita.

Já no modelo 2, avaliou-se a influência da consciência fonológica e do conhecimento de letras (aplicados no primeiro momento) no nível de escrita (aplicado no segundo). A cada aumento de um ponto na consciência fonológica, observou-se um acréscimo de 1,14 pontos no nível de escrita, e a cada aumento de um ponto no conhecimento de letras, observou-se um acréscimo de 1,26 pontos no nível de escrita. Esse modelo explica 55,4\% da variabilidade do nível de escrita.

No modelo 3, referente aos testes aplicados no segundo momento, a cada aumento de um ponto na consciência fonológica, observou-se um aumento de 1,36 pontos no nível de escrita, e a

672 cada aumento de um ponto no conhecimento de letras, houve aumento de 3,43 pontos no nível de escrita. Esse modelo explica 75,3\% da variabilidade do nível de escrita.

Dessa maneira, no modelo 1 , todos os pressupostos para realização da regressão linear foram verificados. Nos modelos 2 e 3, o princípio de homocedasticidade foi violado. Contudo, os resíduos apresentaram distribuição normal em todos os modelos, de acordo com o teste Kolmogorov-Smirnov.

\section{Discussão}

Ao final do $1^{\circ}$ ano, houve uma melhora significativa na consciência fonológica, conhecimento de letras e nível de escrita, em comparação aos meses de março e abril. Esse resultado confirmou as expectativas, pois era esperado que crianças sem distúrbios de aprendizagem evoluíssem nessas habilidades a partir das tarefas de leitura e escrita realizadas no contexto de sala de aula ao longo do ano (Moraes \& Capellini, 2010). 
A escola tem a função de propiciar experiências com a linguagem escrita e estimular a reflexão intencional da criança a respeito das relações entre a linguagem oral e a escrita (Justino \& Barrera, 2012). Neste sentido, o ensino formal sistematizado é fundamental para a aquisição da leitura e escrita (Cárnio, Pereira, Alves, \& Andrade, 2011) e os resultados aqui apresentados mostram que esse papel foi cumprido não apenas para a aprendizagem da escrita, mas também para as capacidades metafonológicas.

Nos dois momentos da avaliação, observou-se que as crianças as quais obtiveram um melhor desempenho em consciência fonológica e em conhecimento de letras apresentaram um nível de escrita mais desenvolvido. Da mesma forma, outros estudos registraram essa relação positiva entre consciência fonológica e escrita (Cardoso et al., 2013; Corrêa \& Cardoso-Martins, 2012; Santos \& Befi-Lopes, 2012; Tenório \& Ávila, 2012), e entre conhecimento de letras e escrita (Cardoso-Martins \& Batista, 2005; Corrêa et al., 2010; Kim, Petscher, Foorman, \& Zhou, 2010; Levin et al., 2002).

A relação entre o conhecimento de letras e o nível de escrita sugere que o conhecimento de uma criança sobre as letras do alfabeto é um suporte fundamental para a aprendizagem das correspondências entre a fala e a sua representação ortográfica, tornando-se um preditor do desempenho que ela apresentará em tarefas de escrita em momentos posteriores (Corrêa et al., 2010; Georgiou et al., 2012). Estudos efetuados com escolares brasileiros mostram que essas crianças iniciam o processo de compreensão do princípio alfabético registrando em suas escritas letras cujo nome pode ser percebido na estrutura sonora das palavras (Cardoso-Martins \& Batista, 2005). A estratégia de conectar a fala à escrita a partir do conhecimento do nome das letras é utilizada por pré-leitores, independentemente da idade ou nível de desenvolvimento (Corrêa et al., 2010). Contudo, no presente estudo, algumas das crianças ainda não tinham adquirido essa percepção, principalmente no primeiro momento da avaliação, mesmo entre aquelas que conheciam o nome da maioria das letras. Daí o fato da correlação entre o conhecimento de letras e o nível de escrita ser apenas moderada no início da aprendizagem. Isso significa que não basta conhecer o nome das letras, é necessário perceber também para que servem e ter capacidade para detectar esses sons nas palavras.

No final do ano letivo, devido ao ensino que as crianças tiveram, a compreensão da relação que se pode estabelecer entre os sons das palavras e as letras que os representam progrediu e estreitou-se e por isso verificou-se uma associação de grande magnitude entre o conhecimento de letras e a escrita. O ensino de letras e da sua relação com a escrita parece, pois, ser um dos componentes importantes da alfabetização.

A consciência fonológica, por outro lado, apresentou correlações de alta magnitude com o nível de escrita nos dois momentos da avaliação e contribuiu para explicar a variabilidade no desempenho em escrita observado entre os escolares. Isso demonstrou que detectar e manipular oralmente sílabas e fonemas nas palavras é essencial para a compreensão das relações grafofonêmicas (Cardoso-Martins, Mesquita, \& Ehri, 2011; Martins, 2010; Santos \& Befi-Lopes, 2012; Tenório \& Ávila, 2012).

É interessante observar que, logo no início do ano letivo, a consciência fonológica, ao contrário do conhecimento de letras, se mostrou fortemente associada à capacidade das crianças para representar a fala pela escrita. Isso sugere que apenas aquelas crianças que tinham melhores habilidades para focar sua atenção nos sons da fala, e não apenas as que conheciam mais letras, estavam em melhores condições para realizar essa tarefa complexa de transformar fala em símbolos gráficos. A consciência fonológica é considerada uma capacidade necessária para o domínio do código alfabético (Justino \& Barrera, 2012), tanto para a habilidade de ler como para a de escrever palavras (Corrêa \& Cardoso-Martins, 2012).

A análise de regressão realizada para os desempenhos obtidos no primeiro momento da avaliação (modelo 1) mostrou que tanto a consciência fonológica quanto o conhecimento de letras são determinantes na produção da escrita alfabética, pois explicavam, em conjunto, mais de $70 \%$ das 
diferenças individuais observadas no início do ano escolar. Nessa altura, a consciência fonológica mostrou ter um peso explicativo um pouco superior ao do conhecimento de letras.

Em contrapartida, no segundo momento da avaliação (modelo 3), o conhecimento de letras foi a variável que melhor predisse o nível de escrita dos escolares. Uma das hipóteses que pode justificar esses resultados é, como sugerido anteriormente, a de que algumas crianças que já conheciam o nome da maioria das letras ainda não haviam desenvolvido de forma satisfatória as habilidades de consciência fonológica e, consequentemente, apresentaram baixo desempenho em escrita no primeiro momento da avaliação. Ao final do ano, grande parte dos escolares tinha alcançado o nível alfabético de escrita, significando que já tinham se apropriado não apenas do conhecimento de letras, mas também da sua relação com os sons da fala.

Outra explicação pode ser o fato da prova de consciência fonológica combinar o processamento de sílabas e fonemas. Essa combinação pode ter sido mais sustentadora da produção de escrita no início do que no final do ano, pois, no final do ano, as escritas eram mais corretas e, portanto, mais especificadas do ponto de vista da relação fonema-grafema. O conhecimento de letras e a consciência fonológica, particularmente a fonêmica, são os dois pilares mais relevantes da construção do conhecimento alfabético. Ambos se influenciam mutuamente e existem provas sólidas da relação bidirecional entre eles (Muter, Hulme, Snowling, \& Stevenson, 2004). Outro estudo confirma a importância da atuação conjunta do conhecimento de letras e da consciência fonológica na aprendizagem da escrita (Martins, 2010). Também foi observado que o desempenho em consciência fonológica e conhecimento de letras no início do ano contribuíram para explicar o desenvolvimento da escrita das crianças ao final do ano.

A partir desses resultados pode-se inferir que as crianças as quais obtiveram um melhor desempenho no início do ano foram as que evoluíram mais no final do ano. Em contrapartida, os alunos

674 que ingressaram na escola apresentando poucos conhecimentos metafonológicos, continuaram, no final do ano, aquém daquelas que já possuíam algum conhecimento. Isso significa que a escola nem sempre consegue atender à diversidade de alunos que chegam no início do ano, nem esbater essas diferenças. Embora tendencialmente todas as crianças aprendam durante um ano escolar, aquelas que iniciaram o processo de aprendizagem menos equipadas com os conhecimentos nucleares para aprender a escrever permanecem no seu posto relativo no fundo da tabela. Ou seja, aquelas que estão mais "atrasadas" com relação aos conhecimentos linguísticos podem vir a apresentar dificuldades no decorrer da aprendizagem caso não sejam assinaladas e recebam um atendimento focado em suas necessidades.

Verificar o modo como o conhecimento de letras progride e como as crianças o usam para representar os sons da fala é uma prática eficaz e necessária para detectar aquelas que precisam de ajuda. Além disso, a partir destes resultados, acredita-se que a estimulação da consciência fonológica, assim como o ensino das letras, deve estar presente desde os primeiros anos da educação infantil, promovendo um eficaz aprendizado do princípio alfabético para desenvolver plenamente habilidades de leitura e escrita (Pestun et al., 2010).

\section{Considerações Finais}

Pode-se concluir que os escolares, de uma maneira geral, evoluíram ao longo do ano nas habilidades de consciência fonológica, conhecimento de letras e nível de escrita. A consciência fonológica e o conhecimento de letras têm uma estreita relação com o desenvolvimento da escrita, relação esta que se mantém do início para o final do ano letivo. Estes resultados contribuem para compreender os fatores que são essenciais para a aprendizagem da escrita e reforçam a necessidade de se trabalhar com a consciência fonológica e conhecimento de letras de forma sistemática na educação infantil. Além disso, a avaliação dessas habilidades pode predizer a progressão em escrita de crianças que estão iniciando o processo de alfabetização. 
Como limitações do estudo, não foram incluídas na pesquisa variáveis educacionais, sociais e outras habilidades as quais possam estar associadas ao desempenho em escrita dos escolares. Também não foram analisadas as habilidades silábicas e fonêmicas separadamente, uma vez que o instrumento utilizado para avaliar a consciência fonológica possui poucos subtestes fonêmicos para crianças menores de 7 anos. Estudos futuros deverão ser conduzidos para identificar outros fatores que possam interferir na aquisição da leitura e da escrita, bem como analisar quais habilidades metafonológicas são mais significativas para a aprendizagem.

\section{Colaboradores}

M.R. BARBOSA participou na concepção e desenho do estudo, coleta de dados, tabulação, discussão dos resultados e elaboração do artigo. L.B.O. MEDEIROS participou na coleta de dados, tabulação e elaboração do artigo. A.P.S. VALE participou na concepção e desenho do estudo, discussão dos resultados e redação final.

\section{Referências}

Abbott, R. D., Berninger, V. W., \& Fayol, M. (2010). Longitudinal relationships of levels of language in writing and between writing and reading in grades 1 to 7. Journal of Educational Psychology, 102(2), 281-298.

Alvarez, A. M. M. A., Carvalho, I. A. M., \& Caetano, A. L. (1998). Perfil de habilidades fonológicas. São Paulo: Via Lettera.

Brites, S. M. R. (2009). Teste das Matrizes Progressivas Coloridas de Raven: estudos psicométricos e normativos com crianças dos 4 aos 6 anos (Dissertação de mestrado não-publicada). Universidade de Coimbra, Portugal.

Capellini, S. A., \& Lanza, S. C. (2010). Desempenho de escolares em consciência fonológica, nomeação rápida, leitura e escrita. Pró-Fono Revista de Atualização Científica, 22(3), 239-244.

Capovilla, A. G. S., Capovilla, F. C., \& Suiter, I. (2004). Processamento cognitivo em crianças com e sem dificuldade de leitura. Psicologia em Estudo, 9(3), 449-458.

Cardoso, A. M. S., Silva, M. M., \& Pereira, M. M. B. (2013). Consciência fonológica e a memória de trabalho de crianças com e sem dificuldades na alfabetização. CoDAS, 25(2), 110-114.
Cardoso-Martins, C., \& Batista, A. C. E. (2005). O conhecimento do nome das letras e o desenvolvimento da escrita: evidência de crianças falantes do Português. Psicologia: Reflexão e Crítica, 18(3), 330-336.

Cardoso-Martins, C., \& Corrêa, M. F. (2008). O desenvolvimento da escrita nos anos pré-escolares: questões acerca do estágio silábico. Psicologia: Teoria e Pesquisa, 24(3), 279-286.

Cardoso-Martins, C., Mesquita, T. C. L., \& Ehri, L. (2011). Letter names and phonological awareness help children to learn letter sound relations. Journal of Experimental Child Psychology, 109(1), 25-38.

Cárnio, M. S., Pereira, M. B., Alves, D. C., \& Andrade, R. V. (2011). Letramento escolar de estudantes de $1^{\mathrm{a}} \mathrm{e}$ $2^{a}$ séries do ensino fundamental de escola pública. Revista da Sociedade Brasileira de Fonoaudiologia, 16(1), 1-8.

Corrêa, M. F., \& Cardoso-Martins, C. (2012). O papel da consciência fonológica e da nomeação seriada rápida na alfabetização de adultos. Psicologia: Reflexão e Crítica, 25(4), 802-808.

Corrêa, M. F., Cardoso-Martins, C., \& Rodrigues, L. A. (2010). O conhecimento do nome das letras e a sua relação com o desenvolvimento da escrita: evidência de adultos iletrados. Psicologia: Reflexão e Crítica, 23(1), 161-165.

Coutinho, S., Vale, A. P., \& Bertelli, R. (2003). Efeitos de transferência de um programa de desenvolvimento de consciência fonêmica no jardim de infância. In F. L. Viana, M. Martins, \& E. Coquet. (Orgs.), Leitura, literatura infantil e ilustração: investigação e prática docente (pp.57-64). São Paulo: Almedina.

Georgiou, G. K., Torppa, M., Manolitsis, G., Lyytinen, H., \& Parrila, R. (2012). Longitudinal predictors of reading and spelling a cross languages varying in orthographic consistency. Reading and Writing, 25(2), 321-346.

Juel, C., Griffith, P., \& Gough, P. (1986). Acquisition of literacy: A longitudinal study of children in first and second grade. Journal of Educational Psychology, 78(4), 243-255.

Justino, M. I. S. V., \& Barrera, S. D. (2012). Efeitos de uma intervenção na abordagem fônica em alunos com dificuldades de alfabetização. Psicologia: Teoria e Pesquisa, 28(4), 399-407.

Kim, Y. S., Petscher, Y., Foorman, B. R., \& Zhou, C. (2010). The contributions of phonological awareness and letter-name knowledge to letter-sound acquisition: A cross-classified multilevel model approach. Journal of Educational Psychology, 102(2), 313-326.

Levin, I., Patel, S., Margalit, T., \& Barad, N. (2002). Letter names: Effect on letter saying, spelling and word recognition in Hebrew. Applied Psycholinguistics, 23(2), 269-300.

Mann, V. (1993). Phoneme awareness and future reading ability. Journal of Learning Disabilities, 4, 259-269. 
Marchetti, P. T., Mezzomo, C. L., \& Cielo, C. A. (2010). Habilidades em consciência silábica e fonêmica de crianças com fala desviante com e sem intervenção fonoaudiológica. Revista da Sociedade Brasileira de Fonoaudiologia, 15(1), 80-87.

Martins, B. D. (2010). Preditores da aprendizagem da leitura e da escrita: comparação entre dois testes de consciência fonológica utilizados em fase pré-escolar (Dissertação de mestrado não-publicada). Universidade de Trás-Os-Montes e Alto Douro, Portugal.

Moraes, M. P., \& Capellini, S. A. (2010). Conhecimento de letras, sílabas e palavras por escolares de $1^{\circ}$ e $2^{\circ}$ anos do ensino fundamental. Revista Psicopedagogia, 27(84), 325-333.

Mota, M. M. E. P., \& Castro, N. R. (2007). Alfabetização e consciência metalinguística: um estudo com adultos não alfabetizados. Estudos de Psicologia (Campinas), 24(2), 169-179. http://dx.doi.org/10.1590/S0103-16 6X2007000200004

Muter, V., Hulme, C., Snowling, M. J., \& Stevenson, J. (2004). Phonemes, rimes and language skills as foundations of reading development: Evidence from a longitudinal study. Developmental Psychology, 40(5), 665-681.

Nunes, C., Frota, S., \& Mousinho, R. (2009). Consciência fonológica e o processo de aprendizagem de leitura e escrita: implicações teóricas para o embasamento da prática fonoaudiológica. Revista CEFAC, 11(2), 207-212.

Pestun, M. S. V., Omote, L. C. F., Barreto, D. C. M., \& Matsuo, T. (2010). Estimulação da consciência fonológica na educação infantil: prevenção de dificuldades na escrita. Psicologia Escolar e Educacional, 14(1), 95-104.

Pollo, T. C., Kessler, B., \& Treiman, R. (2005). Vowels, syllables, and letter names: Differences between young children's spellings in English and Portuguese. Journal of Experimental Child Psychology, 92(2), 161-181.

Raven, J. C., Raven, J., \& Court, J. H. (1988). Matrizes progressivas coloridas de Raven. Manual. São Paulo: Casa do Psicólogo.

Santos, M. T. M., \& Befi-Lopes, D. M. (2012). Vocabulário, consciência fonológica e nomeação rápida: contribuições para a ortografia e elaboração escrita. Jornal da Sociedade Brasileira de Fonoaudiologia, 24(3), 269-275.

Tenório, S. M. P. C. P., \& Ávila, C. R. B. (2012). Processamento fonológico e desempenho escolar nas séries iniciais do ensino fundamental. Revista CEFAC, 14(1), 30-38.

Treiman, R., Kessler, B., \& Pollo, T. C. (2006). Learning about the letter name subset of the vocabulary: Evidence from US and Brazilian preschoolers. Applied Psycholinguistics, 27(2), 211-227.

Verhagen, W. G. M., Aarnoutse, C. J., \& Van Leeuwe, J. F. J. (2010). Spelling and word recognition in grades 1 and 2: Relations to phonological awareness and naming speed in Dutch children. Applied Psycholinguistics, 31(1), 59-80.

Vitor, R. M. (2006). Processamento fonológico e habilidades iniciais de leitura e escrita em pré-escolares: enfoque no desenvolvimento fonológico (Dissertação de mestrado não-publicada). Universidade Federal de Minas Gerais, Belo Horizonte.

Recebido: janeiro 27, 2014

Versão final: maio 23, 2014

Aprovado: setembro 5, 2014 